\title{
AIRPORT SERVICE QUALITY: A RECONCEPTUALIZATION AND A PRACTICAL APPLICATION ON THE NON-AERONAUTICAL SERVICES
}

\author{
Cagri BULUT ${ }^{1,}{ }^{*}$, Sefer AYDOGAN ${ }^{2}$ \\ ${ }^{1}$ Yasar University, Faculty of Business, Izmir, Turkey \\ ${ }^{2}$ National Defence University, Humanity and Social Sciences, Istanbul, Turkey
}

Received 15 April 2019; accepted 29 July 2020

\begin{abstract}
In line with the advancing airway capability, the non-aeronautical business opportunities at airports are also in growth. To attract more passengers or to generate extra income over non-aeronautical services, the airport decision-makers need to evaluate the quality of their services. This study aims at introducing an expanded approach to improve airport service quality aspects of the non-aeronautical business opportunities. Given the increasing number of airports, passengers prefer airports, which provide better or extra services compared to others. To reveal the airport service quality (ASQ) aspects, together with the quality department experts, we conducted a qualitative study that put forward six significant dimensions for an effective evaluation of airport service quality at an airport. Based on the results of the qualitative study, we designed the sector-specific questionnaire, and its empirical data is conducted over 250 passengers through a face-toface survey. Survey results introduce a practical assessment tool for the use of airport managers to gather strategic inputs on their strategic plans and quality implications. Results also contribute to the literature by presenting a comprehensive understanding of the airport service quality.
\end{abstract}

Keywords: service marketing, service practice, service quality and testing, airport services, airport service quality.

\section{Introduction}

Technological developments in the aviation sector have shortened distances. Besides, airports are becoming easy and enjoyable places. So, there is an increasing demand for airports offering such facilities (Bezerra \& Gomes, 2016). The increase in the number of airports allows passengers to prefer airports in terms of a hub, cost, and providing better or extra services unless they have a compulsory choice of airports shaping their journey. In this regard, the airport managers strive to provide attractive, quality services not only because of the potential revenues but also the evolving demands of passengers. Concordantly, there are some factors considered as driving forces related to this perspective. Such as; commercialization and privatization of airports, competitive forces in the airline industry, and the growing expectations of the passengers (Graham, 2013). Either to generate more income for the airports or to increase the overall passenger satisfaction, an effective quality assessment methodology for the airports' non-aeronautical services is a necessity (ACI, 2017; Bezerra \& Gomes, 2015). The measuring necessity of the airport service quality perception has emerged as in every service sector. It is all about identifying what the quality is for the airport service in the eye of passengers.

The international organizations on the quality assurance of the aeronautical services force airports strictly to follow standards. But non-aviation service quality may vary to the competitive position shaped by culture, geography, or linguistics (Arif et al., 2013). To have a generic approach and obtain a scientific solution, the adaptation researches methodology goes on (e.g. Bezerra \& Gomes, 2016; Gonçalves \& Caetano, 2017; Pantouvakis \& Ren$\mathrm{zi}, 2016$ ). Although, there are two models (SERVPERF, Cronin \& Taylor, 1994; SERVQUAL, Parasuraman et al., 1985) to use as the basis for measuring, regarding the unique characteristics of service sectors, the generic methodology and general indicators of SERVQUAL or SERVPERF need to be adapted for a specific measurement of service quality (Sari et al., 2016; Yimga, 2017).

The quality scales have several limitations for the airport managers, regulatory authorities, or sectoral decision-makers (Trischler \& Lohmann, 2018). Besides, the researches (e.g. Gonçalves \& Caetano, 2017; Bezerra \& Gomes, 2016; Pantouvakis \& Renzi, 2016; Tsai et al., 2011) about ASQ are in search of synthesizing practical

*Corresponding author. E-mail: cagri.bulut@yasar.edu.tr

Copyright $\odot 2020$ The Author(s). Published by Vilnius Gediminas Technical University

This is an Open Access article distributed under the terms of the Creative Commons Attribution License (https://creativecommons.org/licenses/by/4.0/), which permits unrestricted use, distribution, and reproduction in any medium, provided the original author and source are credited. 
methodology and quality assessment tools to improve the service standards on international airports in the following countries; e.g. Brazil, Italy, Australia, Chile, Thailand, South Africa, Taiwan, and the USA. The quality factors may differ due to cultural perspective, technological facilities, the areas (Bezerra \& Gomez, 2016) interact with the passengers, and linguistic differences. Hence, there is a difference in delimitation and perspective among the researches (Gonçalves \& Caetano, 2017). The abovementioned researches highlight in common that the quality of airport passenger services, open a context-dependency discussion on which the culture, geographic, linguistic and technologic advances affect, Therefore, the efforts for measuring service quality requests continuity, validation, and modification.

When evaluating the quality of wide range of services offered at an airport, it is stated that the service quality scale should be multidimensional (Bourne et al., 2003) and each dimension should have ingredients the service (Parasuraman et al., 2005). Besides, an integrated approach combining different dimensions is needed for airport service quality measurement (Chenhall, 2005; Kim \& Mauborgne, 2002). The current study is the refinement of the ASQ model blending with a new international airport circumstance in terms of location, culture, linguistic, and extended service areas. It leads a contribution to understand the construct and the attributes resulting in differentiating multidimensionality construct compared to previous researches. Our study is to discover dimensions that would constitute multidimensionality and to present it to be evaluated as generic. There arouses a need for a holistic view on airport services rather than focusing on a relatively narrow scope. Horonjeff et al. (2010) already stated that passengers experience the services from the three major areas of airports (the processing area, the access interface, and the flight interface). Moreover, the quality of the non-aeronautical services within these major areas are the initial experiences influencing the whole vacation (Martín-Cejas, 2006). We consider that expanded scope because, it is important to define the variables affecting the service quality of airports holistically (Gonçalves \& Caetano, 2017) unlike previous researches focus only on the processing area. To do this, we find out what non-aviation services interacting with passengers are in the processing area, access interface, and flight interface areas. Thus, the goal of this study is to go through the attributes causing quality perception related to the nonaeronautical services throughout three major areas by reviewing the multidimensionality of quality conceptualization and aims at providing an expanded ASQ assessment tool for re-conceptualization.

The flow of this article is as follows; the second section is the theoretical background. The third section demonstrates the method of the study and presents the limitations. Forth section reveals the findings of the study.

\section{Theoretical framework}

Zeithaml (1988) describes the service quality notion as superiority or excellence in service delivery that affects passengers and airport management (Fodness \& Murray, 2007; Seth et al., 2005), Thus service quality gains importance not only for the researchers but also for the airport managers. When we browse to the service at the airport, we see reflections of a wide variety of different service sectors. Besides, the simultaneous presentation of different services to passengers makes the nature of the airport complicated. Hence, it may render the understanding of the service quality concept of airport ambiguous. It gets hard especially when the service quality is recognized as a critical success ingredient to differentiate itself from its competitors (Ladhari, 2008) or the airline industry exerts some pressure on the airports by proposing new ways and sophisticated commercial activities (Rhoades et al., 2000). Together with these two effects together, it also helps to increase passenger satisfaction. In other respect, according to the few airports in the past, today's airports compete with each other to attract more passengers. Therefore, measuring the quality of airport services perceived by passengers has been an outcome of that emphasis.

As yet, the literature is in search of producing the ingredients of the airport service quality with a various perspective. While some researchers (e.g. Bezerra \& Gomes, 2016; Arif et al., 2013; Liou et al., 2011; Fodness \& Murray, 2007) reveal quality dimensions, some other researches (e.g. Bogicevic et al., 2013; Chien-Chang, 2012; Han et al., 2012; Correia et al., 2008) propound the quality attributes. Therefore, even though regarding scientific attempts to reach a comprehensive framework of airport service quality construct continue (Fodness \& Murray, 2007), it is generally accepted that it is multidimensional. On the other hand; an effective quality assessment methodology is already in use for different purposes such as benchmarking, private reporting, or advertisement (Fodness \& Murray, 2007). Yeh and Kuo (2003) develop a fuzzy multi-attribute decision-making approach for assessing the passenger service quality of airports. They indicate six dimensions respectively; processing time, convenience, courtesy of staff, information visibility, and security dimensions which can be run for as a benchmarking and management tool. Fodness and Murray (2007) deduce that airport service quality is multidimensional and the efforts on service quality research are limited due to possible homogenized consequences of global expectations. They find out three dimensions namely servicescape, service personnel, and services. Lubbe et al. (2011) stress on the assessment of airport services from the eye of the passengers using the model applied by Fodness and Murray (2007) at the O.R. Tambo International Airport (South Africa). They present three dimensions; interaction, functional and diversion dimensions differentiate among the passengers. To assess the passenger services of the airport and modify the construct, Tsai et al. (2011) develop an integrated 
model. They discover three dimensions namely; physical environment, interaction and outcome, and flight information services at an airport in Taiwan. They also emphasize that the result has a generalization problem. Liou et al. (2011) run another research on airport service quality in Taiwan using the dominance-based-rough set approach. They present eight dimensions; convenience, comfort, ICQ, transportation, courtesy of staff, information visibility, security, and price of shop respectively. Liou et al. (2011) seem to have enriched the evaluation content for the construct by revealing quality expressions such as; immigration (Sohail \& Al-Gahtani, 2005), customs and quarantine, baggage claim, prices at shops, luggage cart, congestion level, telephone and internet which can be considered as the reflections of the technological development and service understanding used in the airport. Pandey (2016) proposes a methodology to prioritize the actions for the requirements of Airports Council International (ACI) through a quality scale. Pandey (2016) puts forward a decision-making methodology on how to select the order of actions to improve the airport service quality. Brida et al. (2016), aim at evaluating service quality in terms of information and communication technologies that may affect airport service quality. They undertake five dimensions; image perception, airport information, terminal servicescape, airport sound information, flight information screen. Jiang and Zhang (2016) aim at assessing the service quality at Melbourne airport by conducting a survey. As an outcome; three dimensions emerged as essential airport services, service items for comfort, convenience and enjoyment, service related to business travel, and baby changing facilities.

Pantouvakis and Renzi (2016) propose a novel multidimensional construct with its measures and test the invariance of those measures across to linguistic differences (English-Italian) from the passengers at Fiumicino Airport, Rome. They stated that servicescape (airport facilities circulation planning attributes, or cleanliness, lighting conditions), signage (signs, flight displays), service (proper training of staff, crowding levels, control procedures, or speed of control) and image (waiting time, shops, or cafes). They are considered as the best description of airports in literature. Bezerra and Gomes (2016) put forward a scale development methodology regarding an assessment by paying attention to the multidimensionality of airport service quality through empirical research at Guarulhos Airport, São Paulo-Brazil. Accordingly, they reach a statistically reliable and valid construct, which has six dimensions; check-in, security, convenience, ambiance, basic facilities, mobility, and prices. They also enrich the multidimensionality construct of ASQ by finding out two new dimensions namely mobility and ambiance dimensions. While mobility dimension involves quality attributes like; wayfinding (a new item), walking distance (Gonçalves \& Caetano, 2017; Pandey, 2016; Liou et al., 2011) and flight information (Brida et al., 2016; Jiang \& Zhang, 2016; Pandey, 2016; Pantouvakis \& Renzi, 2016), ambiance dimension contains cleanliness of airport (Gonçalves \& Caetano, 2017; Pandey, 2016), thermal comfort (Brida et al., 2016; Jiang \& Zhang, 2016), acoustic comfort (Brida et al., 2016). However, each research highlights the multidimensionality of airport service quality is contextdependent by recalling the discussion on the generalization problem of service quality researches.

As to Gonçalves and Caetano (2017), they research small size airports in Brazil ending up with seven dimensions. The small-sized airports host fewer than five million passengers per year, as per Burghouwt's (2012) classification. These are access, check-in, security screening, airport facilities, orientation, comfort, services dimensions. In terms of contributing to the multidimensionality construct. Gonçalves and Caetano (2017) enrich the multidimensionality aspect of the construct by revealing the orientation dimensions. It involves a new combination of indicators such as; walking distance (also indicated by Bezerra \& Gomes, 2016; Gonçalves \& Caetano, 2017; Liou et al., 2011; Pandey, 2016), flight information (also indicated by Bezerra \& Gomes, 2016; Pantouvakis \& Renzi, 2016; Pandey, 2016; Tsai et al., 2011), signs to airport facilities (also indicated by Fodness \& Muray, 2007; Lubbe at al., 2011; Pantouvakis \& Renzi, 2016).

The abovementioned researchers highlight in common that the construct has a context-dependent and multidimensional. Yet, due to the content dependency, we see that the dimensions, number of dimensions and attributes can be different. The models expressing the construct are expected to show the factors and the relationship between the model and the factors (Ghobadian et al., 1994). Therefore, we think about conceptual models of the construct will help decision-makers to manage quality improvement issues that arise in line with evolving passenger requests. However, recent researches on ASQ have also shown that difficulties are defining it as generic. Passenger expectations related to services evolving with global and local factors seem to have led not only to the emergence of new derivative services but also researches to reveal the characteristics of these derivative services. Otherwise, the lack of a "widely accepted ASQ" model will be consolidated. There is an assumption that geographic location in terms of cultural diversity has an impact on the construct. Hence, the construct should be contextualized for the country in which the model exists (Arif et al., 2013). On the other hand; although Horonjeff et al. (2010) indicate three major areas for passenger interaction, the recent literature of measuring the ASQ provides dimensions from mostly at the processing area of airports. Thus, this study revisits the airport service quality conceptualization, considers the three major areas of airports, and aims at presenting an extended assessment tool to determine the quality factors.

\section{Method}

We introduce the research design to develop and test a scale for re-conceptualization passengers' perceptions 
related to service quality. We not only run qualitative and quantitative studies evaluating airport passengers as samples but also deeply search the related literature to generate a quality indicator item pool. We are also interested in focusing on the dimensionality of quality in airport chain services habitat and asses the validity and reliability of the re-conceptualization of the model.

\subsection{Item generation}

We match a qualitative study and a deep literature scan to find out passenger's experiences throughout the three major service areas. We aim at introducing a practical application that will enable the measurement of the nonaeronautical services of the passengers. To achieve this, we decide to expand the scope of the study by taking the areas indicated by Horonjeff et al. (2010) into account. To measure the perceptions of airport passengers regarding passenger service quality, we establish the center of gravity of the research on the interactions between airport passengers and airport passenger services (George et al., 2013; Pantouvakis, 2010). Thus, we aim at re-conceptualizing the measurement of service quality on the cumulative knowledge of related literature together with the light of previous researches. Firstly, to get to know the attributes and the dimensions that make up the construct, we do in-depth research throughout related literature. Therefore, this study runs a systematic literature review method regarding the multidimensionality measurement of airport service quality. Petticrew and Roberts (2006) state that a systematic review of literature intends to identify, appraise, and summarize related researches.

We use the internet as the most important tool to scan and gain periodicals regarding the literature. In particular, the presentation of periodical scientific journals with high impact factors in major databases has increased the speed of performing scientific researches. In this study, we search the studies of related literature in academic journals indexed in scientific databases like Sciencedirect-Elsevier, business source complete-Ebsco, Emerald, and info track. As a constraint of the study; we have limited the content with the studies revealing the ASQ dimensions related to the measurement. Within the scope of the data obtained from these scientific databases; we also limited the scanning with researches published between the years 2007 and 2017. Since the scanning focuses on the multidimensionality measurement of airport service quality, we use the following keyword combinations: airport service quality + measurement. The database presents 170 academic pieces of research in academic journals as the universe. To focus on the aim, we reduce 170 academic research to 28 relevant to the multidimensionality of airport service quality measurement on airport non-aeronautical services perceived by passengers. At last, we consider ten of these researches as the sampling of this study due to the similarity of features and dimensions. Secondly; we reach the airport to observe the services in three service areas indicated by Horonjeff et al. (2010). We compare the dataset obtained from scientific studies with the current passenger services performed at the airport. That allows us to observe changing passenger services under technological advances, cultural and geographical effects. Thirdly; we conduct qualitative research with ten frequently flying passengers to find out new service quality indicators. Fourthly; we run quantitative research to figure out the service quality construct.

\subsection{Sample}

The population of this research constitutes 54 airports located throughout Turkey. As of 2016, 169.36 million passengers used the airports. Since the elements in the universe are not likely to be selected with a certain probability and equal chance, the sample was selected within İzmir Adnan Menderes International Airport in terms of research economy, accessibility to data, and time efficiency. İzmir Adnan Menderes International Airport is the fifth busiest international airport that hosted 12.14 million passengers and 86,998 aircraft traffics.

Due to the too large passenger population, it is practically impossible to cover the population. Moreover; to have the chance of measuring different passenger perceptions regarding airport service quality, we had no inclusion criteria identified before the selection of passengers. Considering these, we have run the convenience sampling method. During interviews, we selected each passenger to participate in our study by convenience sampling of the non-probability sampling method. The convenience sampling method (Saunders et al., 2007) relies on the data collection process from the related population members who are conveniently available at these three main areas of the airport. Before collecting the data, we asked for permission from the airport management for the field researches. Thanks to the airport management that we have reached 250 passengers at the departures in ten weeks with five visits. Since the questionnaires were conducted with one-on-one and faceto-face interviews (Correia \& Wirasinghe, 2007; Park, 1999 ) with the departing passengers, the passengers who had problems answering the statements during the survey filling were immediately assisted by the researchers. Therefore; the percentage of its reversibility is one hundred percent. The characteristics of the sample are as follows: $53.6 \%$ female; $58.4 \%$ married; $17.9 \%$ has high school or lower degree, $67.3 \%$ has a university degree, and $14.7 \%$ has a graduate degree; $18.8 \%$ of the respondents are between 18-24 years old, $29.6 \%$ between $25-34$ years old, $28.5 \% 35-44$ years old, $16.6 \% 45-54$ years old, and $7.5 \%$ over 54 years old. Frequent flyer statistics of the respondents once a month $8.4 \%, 34.4 \%$ at least once in three-months, $41.6 \%$ at least once in six months, and $15.6 \%$ the respondents visit an airport as a passenger at least once in a year. 


\subsection{Scales, questionnaire and data collection}

We run Likert-type items ranging from 1 (strongly disagree) to 5 (strongly agree) (Trischler \& Lohmann, 2018). Moreover, Linkert-type item evaluation allows us to have more elaborated feedbacks about our measurement on airport service quality compared to binary questions. Because it uncovers degrees of passenger perceptions that can make a difference in understanding the airport service quality. Linkert-type item evaluation can also pinpoint the passenger service areas where we want to make some suggestions to managers about improving passenger services in an airport. We selected respondents from the departing passengers. Because departing passengers are the ones who could spend his/her time by benefiting from the passenger services compared to arriving passengers. Besides, the majority of passenger services are designed for departing ones at three major areas of an airport. We have cordially asked any convenient passenger to go with our survey one by one.

The literature also suggests that the determination of the gap between expected and perceived quality of the services from the eyes of the utilizers is important for the performance assessment of service quality (Cronin \& Taylor, 1992). Thus, we aimed to cover each of the service quality dimensions with important keywords at separate lines. Each of the lines asks perceived and expected scores on the quality of dimensions, as depicted in Table 1.

\subsection{Qualitative research}

After a deep literature review, we advanced to the qualitative research between September and December 2015 to determine the appropriate constructs of the research questionnaire for our planned survey. Passengers relate the majority of the services at the airports to the administrations of airports. However, airline companies also provide significant services at airports. Trischler and Lohmann (2018) suggest distinguishing the services of airlines and airports is a necessity for their empirical evidence from Australia. To reach the full understanding of which services the passengers utilize or expect, and which of those services perceived as they are provided by the administrations of airports, we decided to conduct interviews, airport administration, and passengers. Thus, our interviews with the passengers and administration of the Airport's Quality Department aim to clarify the question of what the interacting passenger services within three main areas are?

We conducted face-to-face interviews with three supervisors from the quality management department of Izmir International Airport, Turkey (ADB), and the passengers at the domestic departures. Each of the three supervisors was tenured and expert on quality management with the background of front-line at the airports. We have used a structured interview method with experts in the quality department. It is a type of interview method (Corbetta, 2003) where items are determined in advance and a detailed interview plan is prepared. That allowed us what item to collect with the agreement with quality experts. We have asked the experts of the quality department to answer a set of predefined quality items within predetermined passenger service quality categories. The aim is to determine the difference with the information provided by the interviewed expert, make comparisons accordingly, and improve the scale. The interviewee selection from the passengers is made by asking them several questions on if the participant is a frequent-flyer and using the ADB Airport frequently, as well as if they would like to participate in our qualitative research with a volunteer contribution. Finally, we conducted interviews with ten passengers who frequently use $\mathrm{ADB}$ airport and willing to contribute to our qualitative research. Our interviews with these ten frequently flying passengers continue until the data related to ASQ is self-repeating. Moreover, one of the researchers worked in the aviation sector for 16 years professionally. This advantage has been an important facilitating factor to distinguish the services to be kept and discarded.

We first consolidated the statements of each party as service providers and service utilizers. Second, we

Table 1. Assessment of ASQ quality gap

\begin{tabular}{|c|c|c|c|c|c|c|c|c|c|c|}
\hline \multicolumn{5}{|c|}{ Expected Quality } & \multirow{2}{*}{$\begin{array}{l}\text { Please indicate your expected and perceived quality scores towards the criteria below } \\
\text { Functional Quality; The vehicles for the handicapped and elderly people for boarding the } \\
\text { plane }{ }^{\star} \text {, CIP passenger services, Unattended child services*, Special services }{ }^{\star} \text {, Access to rent } \\
\text { a car service. }\end{array}$} & \multicolumn{5}{|c|}{ Perceived Quality } \\
\hline 1 & 2 & 3 & 4 & 5 & & 1 & 2 & 3 & 4 & 5 \\
\hline 1 & 2 & 3 & 4 & 5 & $\begin{array}{l}\text { Servicescape Quality; Air conditioning, noise pollution, ambient brightness, ambiance, flight } \\
\text { information screens }\end{array}$ & 1 & 2 & 3 & 4 & 5 \\
\hline 1 & 2 & 3 & 4 & 5 & $\begin{array}{l}\text { Ground service quality; Easy transit, transit speed, transportation quality, transportation } \\
\text { safety, cleanness/hygiene }\end{array}$ & 1 & 2 & 3 & 4 & 5 \\
\hline 1 & 2 & 3 & 4 & 5 & Ticketing Quality; Speed of ticketing, reissuing, control/stamping, and refunding & 1 & 2 & 3 & 4 & 5 \\
\hline 1 & 2 & 3 & 4 & 5 & $\begin{array}{l}\text { Security (and confidence) Quality; Efficiency of Security control and efficiency of } \\
\text { information desks and information staff }\end{array}$ & 1 & 2 & 3 & 4 & \\
\hline 1 & 2 & 3 & 4 & 5 & $\begin{array}{l}\text { Comfort quality; Queue management, internet access and speed, kinder playing facilities, } \\
\text { prices at the stores }\end{array}$ & 1 & 2 & 3 & 4 & $J$ \\
\hline
\end{tabular}

Note: ${ }^{\star}$ the items of these keywords are omitted during the multivariate normality assessment. 
evaluated if a service quality-related item covers a statement from the literature. Third, we categorized the perceived services according to the literature and service quality. Fourth, we matched the perceptions of airports' services of two groups and excluded several variables of services in which passengers attributed them either to the airline companies or to other private and independent enterprises, that provide services such as transportation from city-center and valet parking. In brief, we either kept or included the services that the passengers' attribute it as they are under the responsibility of the airport administration or not. Thus, we considered several adjustments according to the context of Turkey; such as participating passengers declared that all around the world passengers use the on-line check-in services frequently if they are available. As different from the literature (e.g. Bezerra \& Gomes, 2015; Trischler \& Lohmann, 2018), the qualitative results showed that the responsibility and the quality of check-in related services are attributed to the airline companies, which we omitted the related statements and items in the literature for our survey research. Appendix-1 presents the perceived services of ASQ. In the table "new item" indicates that a service is codified based on the qualitative research findings and lacking in the literature, whereas citations show the sources of respective perceived airport service which already exists in the literature.

\subsection{Quantitative research and factor analyses}

It is pointed out that the quality construct of different services together should be multidimensional (Bourne et al., 2003) and each dimension should include quality indicators reflecting the service (Parasuraman et al., 2005) and also connoted that an integrated approach gathering different dimensions is needed (Chenhall, 2005; Kim \& Mauborgne, 2002). Therefore; we have run factor analyses (e.g. Bezerra \& Gomes, 2016; Brida et al., 2016; Jiang \& Zhang, 2016; Pantouvakis \& Renzi, 2016) as a scientific method to determine the factors generating airport service quality to reveal the multidimensionality. We have taken a holistic approach in terms of revealing the airport service quality by expanding the perspective of determining the airport service quality, which continues to be an innovative process from previous researches, to cover three major areas of an airport that passengers make use of. Moreover, the assessment of the quality of services provided in certain areas is essentially expected to include development that reflects the features of the services. The literature review lets to select evaluation criteria that can be used to determine the relationship between airport service quality perception and the existing services (Pabedinskaite \& Akstinaite, 2014).

As we have noted before, our field research has two stages. Initial research aims at generating the construct and items to determine the criteria of service quality. The second step aims to purify the measures of the service quality construct, which tests the reliability and the va- lidity of the scale. We aim at putting forward an assessment tool and a clear methodology for practitioners and researchers. We developed the questionnaire after the interviews with passengers through adopting experiences of experts in non-aeronautical service quality. We randomly distributed all of the items into the questionnaire. The questionnaire includes all the items we developed or borrowed from the literature to determine the criteria for assessment. For the second stage, to develop the scale items we initially matched the constructs with the literature and depicted in Appendix-1. We then generated the new items based on both the literature and the presented findings of the interviews.

Before calculating the descriptive statistics, we conducted a series of exploratory factor analyses. Analysis with Varimax rotation and cut-point $>1.0$ eigenvalue resulted in six factors, which support the multidimensionality of the construct and the discriminant validity of the dimensions (KMO: 0.809; and Total Explained Variance: 68.638). Finally, we progressed each group of items into EFA according to its respective factor for testing the multidimensionality. We observed that each of the six dimensions did not produce another factor that provided evidence for the multidimensionality of the scale of each factor. EFA resulted in six factors, where all the factorloading values are above the score of 0.40 . Hence, we have progressed the confirmatory factor analysis to test the theoretical six-dimensional construct. Initially, we analyzed the theoretical model as we have proposed, however, we found marginally acceptable results for ASQ variables that we have derived from the qualitative research $\chi 2 / \mathrm{df}$ : 2.51, GFI: 0.84, AGFI: 0.80, CFI: 0.90, RMSEA: 0.078, and RMR: 0.052.

To achieve a satisfactory model, we tested the multivariate normality. Accordingly, we realized that some variables should be omitted from the functional quality scale, which is "the vehicles for the handicapped and elderly people for boarding the plane", "unattended child services", and "special services for treatments". Those three items have been generated from the suggestions of qualitative research, however multivariate normality assessment provides a perspective that the representative of the usual passenger population on those three items may need another research, which will target the specific information only from the passengers who utilize the respective services individually. After the multivariate normality assessment, we conducted CFA according to our theoretical model and reached satisfactory results for airport service quality instrument $\chi 2 / \delta \phi: 3.48$, GFI: 0.96, AGFI: 0.95, CFI: 0.99, RMSEA: 0.021, and RMR: 0.075, where all factors loaded significantly into its respected items (Table 2). Consequently, except for the omitted three items, we ensured that the theoretical construct is as we proposed.

We have foreseen the airport service quality structure to be multidimensional with the holistic approach to measure airport service quality. However; the new scale has exceeded our predictions in terms of revealing the 
Table 2. The Scale items and CFA factor loadings of airport service quality construct (source: see at Appendix 1 and 2)

\begin{tabular}{|l|c|l|l|}
\hline \multicolumn{3}{|c|}{ ASQ Scale Items } \\
\hline Functional quality (D1) & & Servicescape Quality (D4) & .68 \\
\hline VIP passenger services & .94 & The temperature level of the terminal building & .62 \\
\hline Access to rent a car service. & .98 & Sound comfort of the terminal building & .84 \\
\hline Ground Services Quality (D2) & & The brightness level of the terminal building & .82 \\
\hline Transit speed between gate and plane & .76 & The comfort of the terminal building & .75 \\
\hline Transportation safety of airport vehicles & .78 & Flight information screens at the terminal building \\
\hline Transportation quality of airport vehicles & .80 & Security Quality (D5) & .82 \\
\hline Overall cleanness/hygiene during the transportation & .68 & Access to Information Desks & .92 \\
\hline Easy transit between car parking place and terminal & .59 & The efficiency of security points & .82 \\
\hline Ticketing Quality (D3) & & Respond quality of Information Desks \\
\hline Speed of reissuing the tickets & .80 & Efficient management of the queues & .86 \\
\hline Easy access to the ticket sales office for refunding & .61 & Comfort Quality (D6) & .47 \\
\hline Speed of ticketing & .71 & $\begin{array}{l}\text { Children's play facilities are adequate in recreational / } \\
\text { entertainment places. }\end{array}$ \\
\hline Speed of controlling/stamping the tickets & .40 & Internet access to terminal buildings is sufficient. \\
\hline- & & The prices at the airport shops are convenient \\
\hline- & & $\begin{array}{l}\text { There are no queues during the departure procedures for } \\
\text { passenger services. }\end{array}$ & .75 \\
\hline
\end{tabular}

Table 3. Mean, standard deviation, Cronbach's Alpha reliability and correlation scores

\begin{tabular}{|c|c|c|c|c|c|c|c|c|}
\hline & $\mathrm{M}$ & $\mathrm{SD}$ & Alpha & D2 & D3 & D4 & D5 & D6 \\
\hline D1 & 3.88 & 0.782 & 0.96 & 0.026 & $0.190^{\star *}$ & $0.271^{\star *}$ & $0.343^{\star *}$ & 0.050 \\
\hline D2 & 3.21 & 0.804 & 0.89 & & $0.379^{\star \star}$ & $0.422^{\star *}$ & $0.221^{\star *}$ & $0.291^{\star *}$ \\
\hline D3 & 3.56 & 0.650 & 0.78 & & & $0.311^{\star \star}$ & $0.327^{\star \star}$ & $0.272^{\star \star}$ \\
\hline D4 & 3.40 & 0.804 & 0.93 & & & & $0.349^{\star \star}$ & $0.323^{\star \star}$ \\
\hline D5 & 3.83 & 0.532 & 0.89 & & & & $0.147^{\star}$ \\
\hline D6 & 2.30 & 0.762 & 0.72 & & & & 1 \\
\hline
\end{tabular}

Note: ${ }^{\star} \mathrm{p}<.05^{\star *} \mathrm{p}<.01$.

quality dimensions of the passenger services that were previously discovered. The functional quality, servicescape quality, security quality, and their newly generated passenger services quality indicators within these dimensions are examples of that prediction of previously discovered as passenger service quality dimensions. In terms of new passenger service quality dimensions, we can give ground service quality dimensions, ticketing quality dimensions as examples. Although we have acknowledged the comfort quality dimension in previous researches, its content has evolved due to using of developing technology for passenger services and improvements in service understanding.

We also calculated the internal consistency of the respective measures by running Cronbach's alpha tests, Table 3 presents the descriptive statistics, the reliabilities (Cronbach's alpha are in the diagonal axis) and correlation scores of each construct across each other.

Due to the Cronbach's Alpha values of more than 0.70, all quality dimensions are reliable. All quality dimensions are positively and significantly related to each other and the overall instrument. It means that all dimensions are consistent and stable in measuring airport service quality. It also indicates that quality dimensions meant to assess the same ASQ construct yield similar scores (Hays \& Revicki, 2005). To understand the central tendency and relative performance, related mean (M) of each dimension shows the values falling around. According to the five-anchor Likert scales, the average score of the service quality indicators included in the relevant dimension is agreed and around. We have low standard deviations. They state that most of the passenger's quality scores are close to the means. That allows us to determine that our new expanded quality measurement agrees with the theoretical prediction based on the airport service quality literature.

There are only the performance findings of the airport service quality remain; we calculated the mean for each dimension and compared both of the expected and perceived scores to understand the service quality gap. We see in Figure 1 that the expected quality performances in all dimensions are higher than the perceived quality performances. 


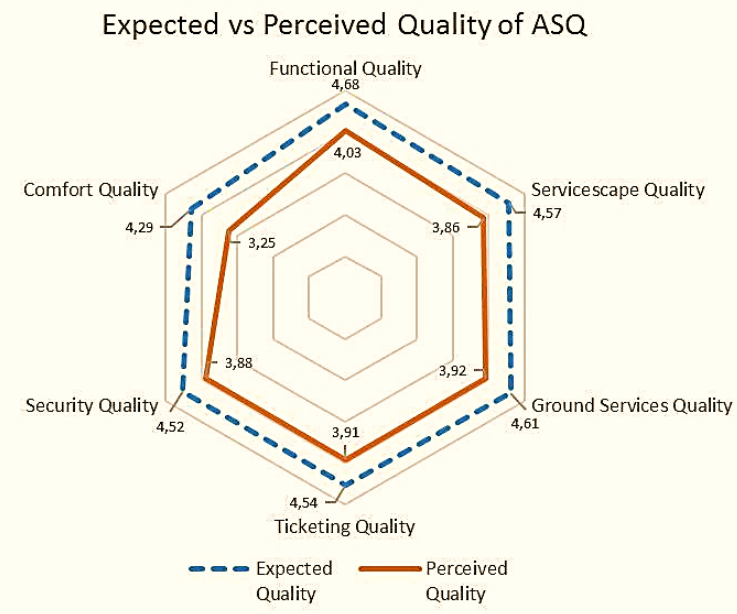

Figure 1. Expected vs. perceived quality of airport service quality

Passenger perceptions regarding services provided for passengers at the airport do not meet the passenger's expectations for services. At these points, there come up quality gaps regarding every passenger quality dimensions.

These quality gaps demonstrate that passenger expectations are not met can lead to dissatisfaction for the passengers. Moreover, to put forward a user-friendly interpretation we decided to use an excel radar chart. It helps to illustrate the quality gap. To show the gaps between expectations and perceptions, Figure 1 sketches the airport service quality with their respective performance evaluation. Respectively; the expected functional quality is 4.68 , perceived is 4.03; the expected servicescape quality is 4.57 , perceived is 3.86; the expected ground service quality is 4.61 , perceived is 3.92 ; the expected ticketing quality is 4.54 , the perceived is 3.91 ; the expected security quality is 4.52 , the perceived is 3.88 and the expected comfort quality is 4.29 , the perceived is 3.25 . Among all perceived dimensions, whereas the comfort quality dimension has the lowest performance (3.25), the functional quality has the highest (4.03). Conversely, among all expected dimensions, whereas the comfort quality dimension again has the lowest performance (4.29), thefunctional quality again has the highest (4.68). Since none of the perceived quality dimensions exceeds the expectations. All the dimensions are above the anchors average of 2.5.

\section{Findings}

The first phase of this study is qualitative research, which puts forward a couple of new indicators other than the airport service quality literature has indicated so far. In addition to the customized items and scales of the literature, findings of the qualitative results have provided new items to the questionnaire as they are depicted in the Appendix-2. Accordingly, we present a practical expanded quality scale with six dimensions as our findings. The quality services measurement tool consists of six dimensions and twenty-five items. Two of these six dimensions have just emerged because of the expansion of service areas. These two new distinct different dimensions are ground service quality and ticketing quality. We also see that the other four dimensions are partially altered. Per that, eleven of twenty-five quality items are new. We also present a practical expanded quality-gap reporting approach partially decorated with new quality items and dimensions. That shows us that passenger perceptions regarding services are lower than passenger expectations regarding services.

Based on the results of qualitative research, the scale of our study has a multidimensional construct too. That is also consistent with the growing body of the literature. Based on the qualitative research results, we assigned each of the services to an airport service quality dimension and decided on a six-dimensional theoretical construct, which we elaborate them below. They are (1) functional quality, (2) servicescape quality, (3) ground services quality, (4) ticketing quality, (5) security quality, and (6) comfort quality.

Functional quality; It refers to the on-demand or bymembership special services and it is the degree of meeting the special needs of passengers (Olsen et al., 1998). Thus, functional quality is related to meeting and exceeding the special needs of the passengers particularly in three segments. The first segment is the passengers who are disabled, elder, or have reduced mobility. The second segment is the passengers who can fly by special permissions like unattended children. The third segment is the passengers who get used to special deals, treatments, or indulgences, such as renting a car at arrivals or using CIP or lounge services at departures. The third segment's passengers either use their memberships and loyalty programs or pay at-the-door for those special services.

For each of the three segments of functional quality, passengers need to ask the needed special service in advance or already hold membership or a loyalty program. Thus, we kept the functional quality as one of the major dimensions of airport service quality consistent with the literature (Lubbe et al., 2011). 
Servicescape quality; It refers to the ambiance and physical environment at the indoor-settings of airports. It includes indoor comfort such as heat, noise, illuminance, and easy access to information screens at the terminal buildings. It affects all passengers' physical condition. The degree of quality is dependent on the infrastructure of the terminal. In our study, they are consisted of five criteria that are (1) the temperature level of the terminal building, (2) sound comfort of the terminal building, (3) the brightness level of the terminal building, (4) the comfort of the terminal building, and (5) flight information screens at the terminal building.

There are more descriptions regarding the servicescape quality such as lightning, safety perception, the cleanliness at the airport, or the efficacy of airport air-conditioning. Thus, we think that the servicescape describes the services in the relevant area more comprehensively.

The literature on the servicescape (Brida et al., 2016; Pantouvakis \& Renzi, 2016) clearly states that ambiance and physical environment influence people's shopping and purchasing behaviors. When the decision-makers of airports plan to renovate the existing premises or construct new buildings, the feedback of passengers on the perceived quality of servicescape will be the core inputs re-assuring the servicescape quality. The good quality of indoor spaces conditions within an airport increases passengers' staying time at the stores and the restaurants instead of arriving on time or waiting at the gates.

Consistent findings in the recent literature state that Bezerra and Gomes (2016) put forward a similar dimension namely ambiance; Gonçalves and Caetano (2017) mark cleanliness of airport facilities quality indicator in the comfort dimension; Pandey (2016) states cleanliness and ambiance of airport terminal indicators in environment dimension; Liou et al. (2011) point out the cleanliness of the environment in comfort dimension and Tsai et al. (2011) exude environment beauty and cleanliness indicator in a physical environment. Brida et al. (2016) have one step further to shape the servicescape dimension and call it terminal servicescape dimension using terminal cleanliness, temperature, noise level which also indicated by Bezerra and Gomes (2016) in ambiance dimension. In parallel with our study, Pantouvakis and Renzi (2016) specify the cleanliness at the airport quality indicator in servicescape and image. We keep the servicescape quality is another critical dimension of the airport service quality with a broader understanding.

Ground services quality; It covers the passenger transportation beginning from the entrance to stepping into aircraft and from aircraft to the exit. The passengers attribute ground services quality to the airport vehicles, escalators, conveyors, piers, and even access to car parking slots. In our study; ground service quality includes (1) transportation safety, (2) speed, (3) easy transit, (4) transportation quality, and (5) hygiene factors related to ground transitions and transports, within the airport and its premises.

As the common denominator of such services is transportation at the airport, we call ground services as a new dimension of airport service quality. Pandey (2016) points out the ground transportation quality indicator in access dimension, Lubbe et al. (2011) identify a variety of ground transportation quality indicator in function dimension, Liou et al. (2011) pint out the ground transportation in transportation dimension. Yet none of them reveal ground services in that detail compared to our study. On the other hand, the ground services are both dependent on services provided airport management and its subsidiaries. In any case, according to passenger interviews, we see that the negative feedback related to the ground service quality mostly target the airline companies instead of the management of the airport. The competitive advantage of an airport strongly relies on the ground services. Because, the cost of a negative comment about ground services from one airline company is high (Lohmann \& Trischler, 2017). Moreover, passengers expect improvements in ground-services (Rhoades et al., 2000). Airline companies make their decisions to the quality of ground services which airport provides to the aircrew and their passengers. Thus, we present the ground services quality as a new dimension for the concept.

Ticketing quality; refers to the speed and accurate ticketing processes rather than the ticket price which has an impact on choosing the airport (Pabedinskaite \& Akstinaite, 2014). The passenger interaction with the ticketing process takes place in the processing area by way of airport management or subcontractor that is also in the responsibility of airport management. The passengers perceive the ticketing process interaction is in four categories; purchasing, reissuing, stamping, and refunding. Booking or on-line booking systems are the services that passengers can obtain with the mobile application of relevant airlines. That's why we keep these two out of our study.

When the passengers arrive at the airport, they sometimes run into the measures stemming from changing weather conditions, sagging of flight times, airport security, and flight safety. These measures lead to changes in scheduled flight times and sometimes in-flight legs leading to the destination. Considering that passengers want to complete their journey safely in a short time, this often turns out to be a stressful and boring problem rather than a sweet surprise for passengers. The management of this stress-filled new flight planning process is becoming important for passengers. In such cases, the passengers apply to the ticket offices located within the airport. During such a process, easy access to the ticket offices and effective utilization of ticket offices, which seem to have a good effect on passenger's leisure time and passenger quality perception, are crucial factors for passengers. As long as the ticketing processes become fast, the passengers will be able to advance to the leisure and shopping spaces of the terminals. Thus, we also propose that the ticketing quality is another new dimension of airport service quality construct, unlike other researches, emphasize the importance of it.

Security (and confidence) quality; It refers to being in confidence. It seems to be related to quality at security matters (e.g ID and ticket control). Gonçalves and Caetano (2017) define security screening, courtesy of the 
security staff, and helpfulness of the security staff as a security screening dimension. Bezerra and Gomes (2016) put forward security screening, courtesy of the security staff, helpfulness of the security staff, and security checkpoints in the security dimension. Surprisingly, Pantouvakis and Renzi (2016) assert the competence of security control employees, speed of security control, courtesy, and helpfulness of security staff in-service dimension.

Other than traditional security perception, being in confidence for a flight passenger also depends on the availability of face-to-face information points or desks when passengers need to receive in a short time. When passengers get answers, they will be more confident to spend quality of a good time in the leisure and shopping areas at the airports. Security quality relies on the number of security points, the speed of security points, and receiving the good quality of information from the information desks when it is needed. Therefore, we kept the security quality as one of the leading indicators of the airport service quality.

Comfort Quality; It refers to the complementary services, which increase passenger's overall motivation towards an airport. There are certain expectations of passengers such as internet services, good line systems (or no queues), and particularly for families with children's availability of playgrounds. We understood that the lack of comfort quality services does not lessen the passenger satisfaction. On the contrary, the readiness of comfort services may bring passengers to the terminal buildings earlier and increase the staying time at the airports. Therefore, the airports with the high quality of comfort services are likely to transform passengers into potential consumers at the leisure and shopping areas. Consequently, we employed the comfort quality as another indicator of the airport service quality.

The current study confirms the previous researches that ASQ is multidimensional (see Appendix-2). The new construct involves six dimensions and 25 items. Two of these six dimensions have just emerged. Four service quality dimensions are partially changed. Herein these dimensions with similar names are enriched in terms of content. We reveal that some of the dimensions have similar characteristics with the previous researches and they may not be dependent on the contexts. Such as; servicescape quality, security quality, comfort quality, and functional quality. However, there are some conspicuous distinctnesses. For instance; the comfort quality of the previous studies generally relates to cleanliness and sanitation of restrooms, lounges, or facilities (e.g. Fodness \& Murray, 2007; Correia et al., 2007; Liou et al., 2011; Gonçalves \& Caetano, 2017; Han et al., 2012; Yeh \& Kuo, 2003). Yet, the previous reserches appear to have found an expansion in passenger perceptions of the variety of services related to the comfort quality dimensions. Such as; moving walkways and escalators, children's playing area, speed of baggage delivery, battery recharge facilities, airport shopping, art displays, music in the terminal, natural light in the terminal, smoking area, the temperature in the terminal. Our study also adds a new indicator to the comfort quality dimensions such as; no queues in departure procedures and also confirms one other; internet access (Gonçalves \& Caetano, 2017; Jiang \& Zhang; 2016; Liou et al., 2011; Pandey, 2016). It is also possible to observe a similar case in the evolution of the functional quality dimension across the researches. The functional quality dimension (Fodness \& Murray, 2007) emphasizes the benefit obtained from the relationship between the devices at the airport and the passengers in terms of efficiency and effectiveness. In our study, we have enriched the content of the functional service dimension determined in previous studies by adding the services offered to passengers with a special need. In our study, the functional quality dimension is mostly focused on disabled passengers, child passengers, and passengers with a special need.

\section{Conclusions}

With short intervals due to developing technology and passenger requests, we have witnessed reflections of a wide variety of different service sectors within the airport. The related literature puts forward various methodologies in a complex manner including differences at items and dimensions in terms of name, numbers and content which causes no generic multidimensional measurement scale for airport non-aeronautical services. Considering that the previous researches focus only on the processing area. The main contribution of this study puts forward a customized quality management assessment instrument specific to the non-aeronautical services of airports based on service quality literature, technology, evolving passenger needs and a holistic approach involving three major areas. Addition to that the practical expanded quality-gap reporting approach reveals that the decision-makers should improve the passenger service quality. It helps decisionmakers where to focus as a strategic priority.

The current study indicates that non-aeronautical services at three major areas are important for the passengers. As a result; the expanded quality evaluating approach suggests a practical tool for decision-makers in a userfriendly format by avoiding complex manner. It produces six service quality dimensions which are emerged from the diversified and expanded services via technology and multi-cultural people habitat. It is an innovative contribution to the efforts regarding resolving the lack of a "widely accepted airport service quality" model. This study confirms that ASQ is multidimensional. Accordingly, several dimensions such as servicescape quality, security quality, and comfort quality have similar characteristics with the previous researches and they may not be dependent on the contexts. Future research can deepen each of the dimensions to produce inputs for the decision-making process or link.

ASQ dimensions to the organizational performance indicators such as the financial performance of the airports. Hence, the literature is lack of other predictions or causal relations such as, which other factors or actors 
benefit from the quality management of airport services. Those findings may produce inputs for the decision-makers who make policies for regional development. The sample is from a large international airport in an emerging economy. Further studies can test the applicability and differences of the airport service quality dimensions at hubairports or small-size airports.

\section{References}

ACI. (2017). Airport-Service-Quality/Customer-Experience-ASQ. Airports Council International. http://www.aci.aero/Customer-Experience-ASQ/Homepage

Arif, M., Gupta, A., \& Williams, A. (2013). Customer service in the aviation industry - An exploratory analysis of UAE airports. Journal of Air Transport Management, 32, 1-7. https://doi.org/10.1016/j.jairtraman.2013.05.001

Badawi, G. (2012). Delivering quality services-Austin style. Airport Management, 6(4), 329-338.

Bezerra, G. C. L., \& Gomes, C. F. (2015). The effects of service quality dimensions and passenger characteristics on passenger's overall satisfaction with an airport. Journal of Air Transport Management, 44, 77-81. https://doi.org/10.1016/j.jairtraman.2015.03.001

Bezerra, G. C. L., \& Gomes, C. F. (2016). Performance measurement in airport settings: a systematic literature review. Benchmarking: An International Journal, 23(4), 1027-1050. https://doi.org/10.1108/BIJ-10-2015-0099

Bogicevic, V., Yang, W., Bilgihan, A., \& Bujisic, M. (2013). Airport service quality drivers of passenger satisfaction. Tourism Review, 68(4), 3e18. https://doi.org/10.1108/TR-09-2013-0047

Bourne, M., Neely, A., Mills, J., \& Platts, K. (2003). Why some performance measurement initiatives fail: Lessons from the change management literature. International Journal of Business Performance Management, 5(2-3), 245-269. https://doi.org/10.1504/IJBPM.2003.003250

Brida, J. G., Moreno-Izquierdo, L., \& Zapata-Aguirre, S. (2016). Customer perception of service quality: The role of Information and Communication Technologies (ICTs) at airport functional areas. Tourism Management Perspectives, 20, 209216. https://doi.org/10.1016/j.tmp.2016.09.003

Burghouwt, G. (2012). Airline network development in Europe and its implications for airport planning. Ashgate Publishing, Ltd.

Chenhall, R. H. (2005). Integrative strategic performance measurement systems, strategic alignment of manufacturing, learning, and strategic outcomes: An exploratory study. Accounting, Organizations, and Society, 30(5), 395-422. https://doi.org/10.1016/j.aos.2004.08.001

Chien-Chang, C. (2012). Evaluating the quality of airport service using the fuzzy multi-criteria decision-making method: A case study of Taiwanese airports. Expert Systems, 29(3), 246-260. https://doi.org/10.1111/j.1468-0394.2010.00574.x

Corbetta, P. (2003). Social research theory, methods, and techniques. SAGE Publications. https://doi.org/10.4135/9781849209922

Correia, A. R., \& Wirasinghe, S. C. (2007). Development of level of service standards for airport facilities: Application to Sao Paulo International Airport. Journal of Air Transport Management, 13(2), 97-103.

https://doi.org/10.1016/j.jairtraman.2006.10.002

Correia, A. R., Wirasinghe, S. C., \& de Barros, A. G. (2008). A global index for level of service evaluation at airport passenger terminals. Transportation Research Part E: Logistics and Transportation Review, 44(4), 607-620. https://doi.org/10.1016/j.tre.2007.05.009

Cronin, J. J. Jr., \& Taylor, A. S. (1992). Measuring service quality: A re-examination and extension. Journal of Marketing, 56(3), 55-68. https://doi.org/10.2307/1252296
Cronin, J. J. Jr., \& Taylor, S. A. (1994). SERVPERF versus SERVQUAL: Reconciling performance-based and perceptions-minus-expectations measurement of service quality. Journal of Marketing, 58(1), 125-131. https://doi. org/10.1177/002224299405800110

Fernandes, E., \& Pacheco, R. R. (2010). A quality approach to airport management. Quality \& Quantity, 44(3), 551-564. https://doi.org/10.1007/s11135-008-9212-9

Fodness, D., \& Murray, B. (2007). Passengers' expectations of airport service quality. Journal of Services Marketing, 21(7), 492-506. https://doi.org/10.1108/08876040710824852

George, B., Henthorne, T. L., \& Panko, R. T. (2013). ASQual: measuring tourist perceived service quality in an airport setting, International Journal of Business Excellence, 6(5), 526536. https://doi.org/10.1504/IJBEX.2013.056093

Ghobadian, A., Speller, S., \& Jones, M. (1994). Service quality: concepts and models. International Journal of Quality \& Reliability Management, 11(9), 43-66. https://doi.org/10.1108/02656719410074297

Gonçalves, M. W. E., \& Caetano, M. (2017). Airport level of service: a model according to departing passenger's perceptions at a small-sized airport. Journal of Airline and Airport Management, 7(1), 65-79. https://doi.org/10.3926/jairm.65

Graham, A. (2013). Managing airports: An international perspective (4th ed.). Routledge. https://doi.org/10.4324/9780080473284

Han, S., Ham, S. S., Yang, I., \& Baek, S. (2012). Passengers' perceptions of airline lounges: Importance of attributes that determine usage and service quality measurement. Tourism Management, 33(5), 1103-1111.

https://doi.org/10.1016/j.tourman.2011.11.023

Hays, R., \& Revicki, D. A. (2005). Reliability and validity (including responsiveness). In Assessing quality of life in clinical trials, 2, 25-39. Oxford University Press.

Horonjeff, R., McKelvey, F. X., Sproule, W. J., \& Young, S. B. (2010). Planning and design of airports. McGraw-Hill.

Janic, M. (2003). Assessment and management of quality of service at an airport passenger terminal. Transportation Planning and Technology, 26(3), 239-263.

https://doi.org/10.1080/03081060320001544601

Jiang, H., \& Zhang, Y. (2016). An assessment of passenger experience at Melbourne Airport. Journal of Air Transport Management, 54, 88-92. https://doi.org/10.1016/j.jairtraman.2016.04.002

Kim, W. C., \& Mauborgne, R. (2002). Charting your company's future. Harvard Business Review, 80(6), 76-83.

Kuo, M. S., \& Liang, G. S. (2011). Combining VIKOR with GRA techniques to evaluate service quality of airports under fuzzy environment. Expert Systems with Applications, 38(3), 13041312. https://doi.org/10.1016/j.eswa.2010.07.003

Ladhari, R. (2008). Alternative measures of service quality: a review. Managing Service Quality: An International Journal, 18(1), 65-86. https://doi.org/10.1108/09604520810842849

Liou, J. J., Tang, C. H., Yeh, W. C., \& Tsai, C. Y. (2011). A decision rules approach for improvement of airport service quality. Expert Systems with Applications, 38(11), 13723-13730. https://doi.org/10.1016/j.eswa.2011.04.168

Lohmann, G., \& Trischler, J. (2017). License to build, license to charge? Market power, pricing and the financing of airport infrastructure development in Australia. Transport Policy, 59, 28-37. https://doi.org/10.1016/j.tranpol.2017.06.009

Lubbe, B., Douglas, A., \& Zambellis, J. (2011). An application of the airport service quality model in South Africa. Journal of Air Transport Management, 17(4), 224-227. https://doi.org/10.1016/j.jairtraman.2010.08.001

Martín-Cejas, R. R. (2006). Tourism service quality begins at the airport. Tourism Management, 27(5), 874-877. https://doi.org/10.1016/j.tourman.2005.05.005 
Olsen, M. D., Ching-Yick Tse, E., \& West, J. J. (1998). Strategic management in the hospitality industry ( $2^{\text {nd }}$ ed.). Van Nostrand Reinhold.

Pabedinskaite, A., \& Akstinaite, V. (2014). Evaluation of the airport service quality. Procedia - Social and Behavioral Sciences, 110, 398-409. https://doi.org/10.1016/j.sbspro.2013.12.884

Pandey, M. M. (2016). Evaluating the service quality of airports in Thailand using fuzzy multi-criteria decision-making method. Journal of Air Transport Management, 57, 241-249. https://doi.org/10.1016/j.jairtraman.2016.08.014

Pantouvakis, A. (2010). The relative importance of service features in explaining customer satisfaction: a comparison of measurement models. Managing Service Quality: An International Journal, 20(4), 366-387.

https://doi.org/10.1108/09604521011057496

Pantouvakis, A., \& Renzi, M. F. (2016). Exploring different nationality perceptions of airport service quality. Journal of Air Transport Management, 52(C), 90-98. https://doi.org/10.1016/j.jairtraman.2015.12.005

Parasuraman, A., Zeithaml, V. A., \& Berry, L. L. (1985). A conceptual model of service quality and its implications for future research. Journal of Marketing, 49(4), 41-50. https://doi.org/10.1177/002224298504900403

Parasuraman, A., Zeithaml, V. A., \& Malhotra, A. (2005). ESQUAL: A multiple-item scale for assessing electronic service quality. Journal of Service Research, 7(3), 213-233. https://doi.org/10.1177/1094670504271156

Park, Y. (1999). A methodology for establishing operational standards of airport passenger terminals. Journal of Air Transport Management, 5(2), 73-80. https://doi.org/10.1016/S0969-6997(98)00040-4

Petticrew, M., \& Roberts, H. (2006). Systematic reviews in the social sciences: a practical guide. Blackwell. https://doi.org/10.1002/9780470754887
Rhoades, D. L. , Waguespack, Jr B., \& Young, S. (2000). Developing a quality index for US airports. Managing Service Quality: An International Journal, 10(4), 257-262. https://doi.org/10.1108/09604520010373136

Saunders, M., Lewis, P., \& Thornhill, A. (2007). Research methods in business studies ( $4^{\text {th }}$ ed.). Prentice-Hall.

Sari, F. O., Bulut C., \& Pirnar, I. (2016, April). Adaptation of hospitality service quality scales for marina services. International Journal of Hospitality Management, 54, 95-103. https://doi.org/10.1016/j.ijhm.2016.02.004

Seth, N., Deshmukh, S. G., \& Vrat, P. (2005). Service quality models: a review. International Journal of Quality \& Reliability Management, 22(9), 913-949. https://doi.org/10.1108/02656710510625211

Sohail, S. M. \& Al-Gahtani, A. S. (2005). Measuring service quality at King Fahd international airport. International Journal of Services and Standards, 1(4), 482-493. https://doi.org/10.1504/IJSS.2005.007473

Tsai, W.-H., Hsu, W., \& Chou, W.-Ch. (2011). A gap analysis model for improving airport service quality. Total Quality Management, 1025-1040. https://doi.org/10.1080/14783363.2011.611326

Trischler, J., \& Lohmann, G. (2018). Monitoring quality of service at Australian airports: A critical analysis. Journal of Air Transport Management, 67, 63-71. https://doi.org/10.1016/j.jairtraman.2017.11.004

Yeh, C. H., \& Kuo, Y. L. (2003). Evaluating passenger service of Asia-Pacific international airports. Transportation Research Part E, 39(1), 35-48. https://doi.org/10.1016/S1366-5545(02)00017-0

Yimga, J. (2017). Airline on-time performance and its effects on consumer choice behaviour. Research in Transportation Economics, 66, 12-25. https://doi.org/10.1016/j.retrec.2017.06.001

Zeithaml, V. A. (1988). Consumer perceptions of price, quality, and value: a means-end model and synthesis of evidence. Journal of Marketing, 52(3), 2-22. https://doi.org/10.1177/002224298805200302 


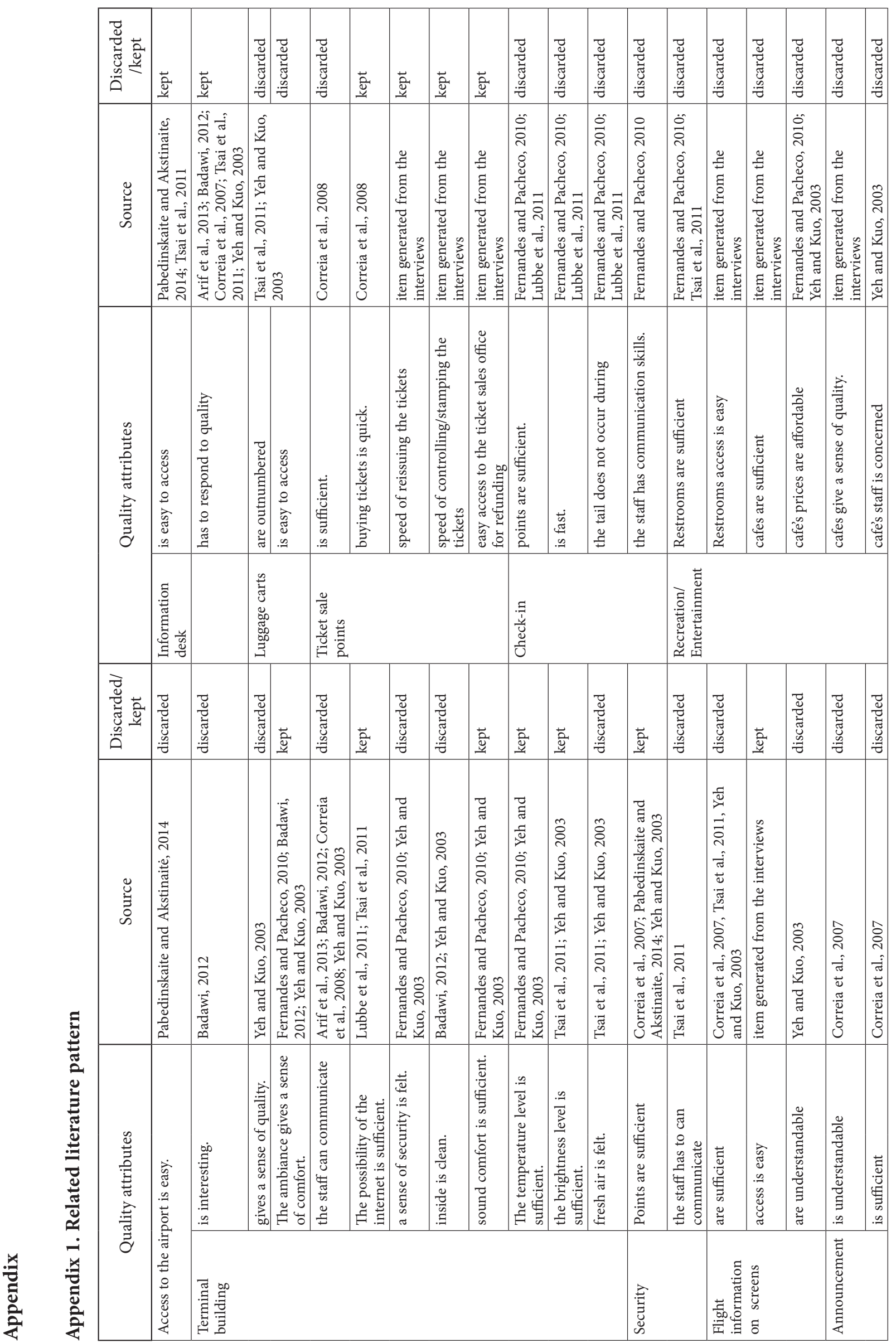




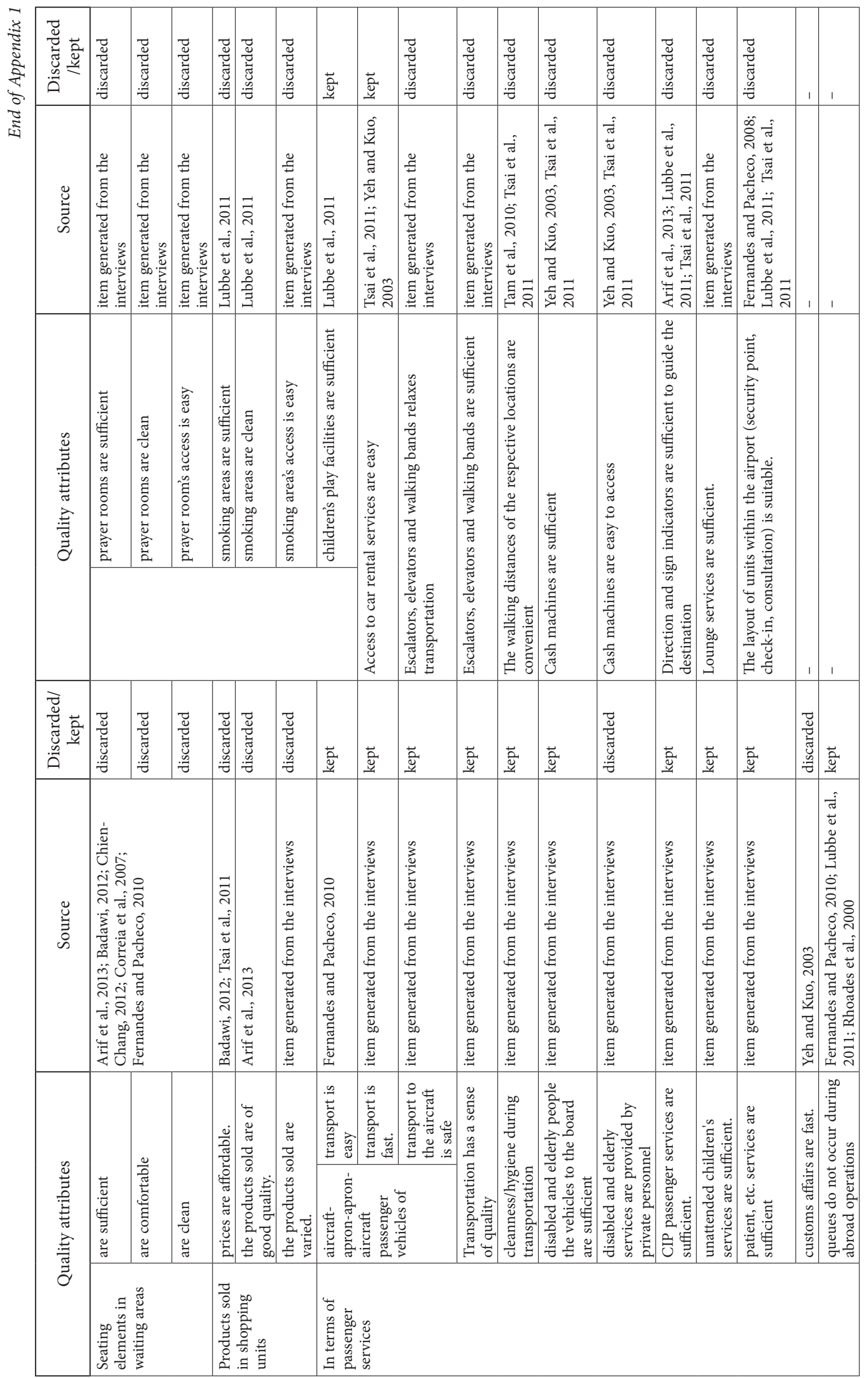




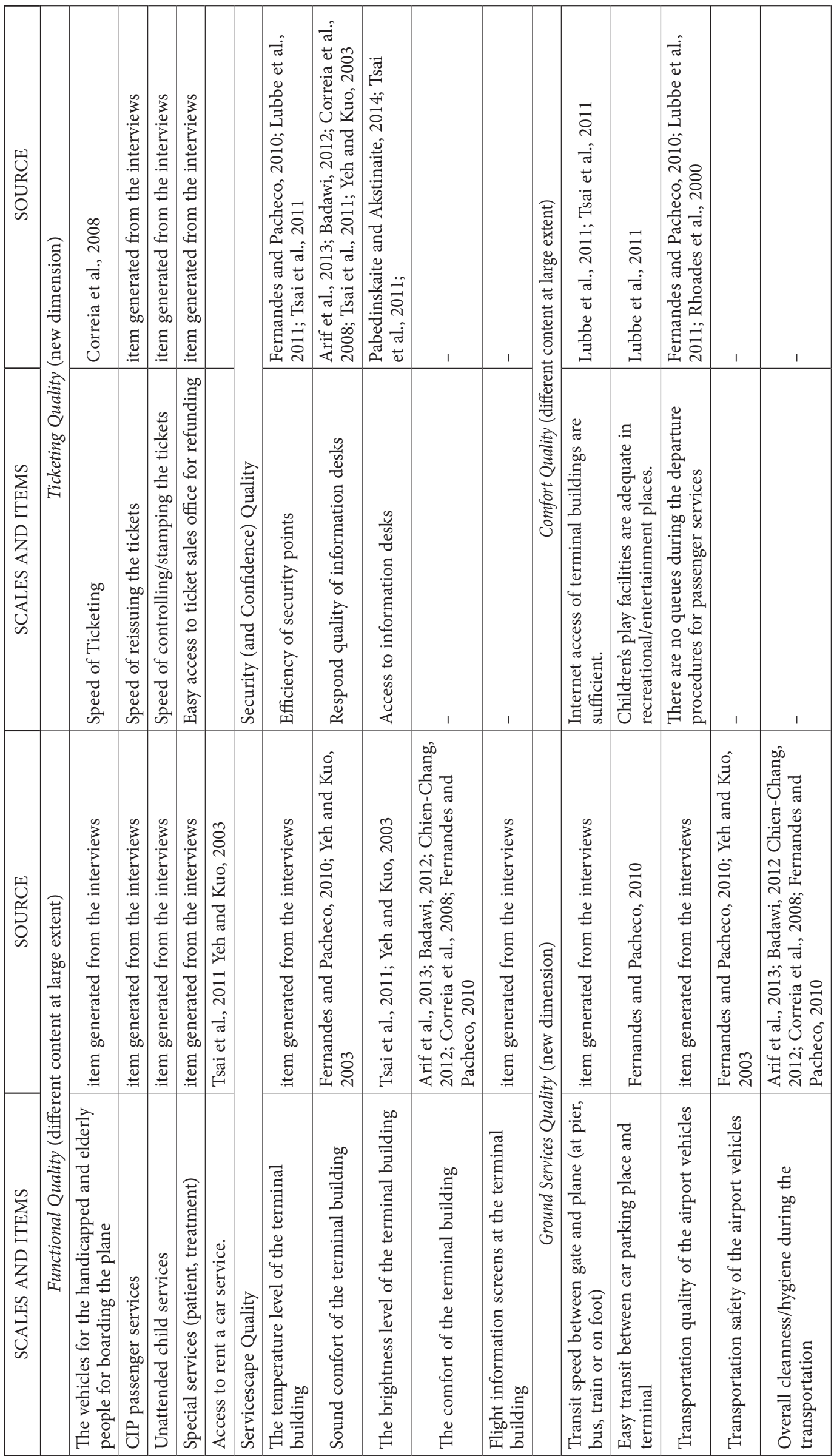

